\title{
Component-based structural equation modeling for the assessment of psycho-social aspects and performance of athletes
}

\section{Measurement and evaluation of swimmers}

\author{
Rosa Fabbricatore ${ }^{1}$ Maria lannario ${ }^{2}$ (D) . Rosaria Romano ${ }^{3}$. \\ Domenico Vistocco ${ }^{2}$ (D)
}

Received: 11 December 2020 / Accepted: 20 July 2021 / Published online: 31 August 2021

(c) The Author(s) 2021

\begin{abstract}
Recent studies have pointed out the effect of personality traits on athletes' performance and success; however, fewer analyses have focused the relation among these features and specific athletic behaviors, skills, and strategies to enhance performance. To fill this void, the present paper provides evidence on what personality traits mostly affect athletes' mental skills and, in turn, their effect on the performance of a sample of elite swimmers. The main findings were obtained by exploiting a component-based structural equation modeling which allows to analyze the relationships among some psychological constructs, measuring personality traits and mental skills, and a construct measuring sports performance. The partial least squares path modeling was employed, as it is the most recognized method among the componentbased approaches. The introduced method simultaneously encompasses latent and emergent variables. Rather than focusing only on objective behaviors or game/race outcomes, such an approach evaluates variables not directly observable related to sport performance, such as cognition and affect, considering measurement error and measurement invariance, as well as the validity and reliability of the obtained latent constructs. The obtained results could be an asset to design strategies and interventions both for coaches and swimmers establishing an innovative use of statistical methods for maximizing athletes' performance and well-being.
\end{abstract}

Keywords Athletes' performance · Latent and emergent variables · PLS-PM · Component-based structural equation models

Maria Iannario

maria.iannario@unina.it

Extended author information available on the last page of the article 


\section{Introduction}

Throughout the past decade, the use of statistical modeling in the analysis of sport performance has gained a rapidly increasing interest. In the approximate 20 years, there has been a remarkable change in both the collection of sports data and the opportunities to address sports questions using statistical models. Methods for measurement and evaluation of player performance have become a relevant issue as such as the prediction of game outcomes or the study of experimental sports science data involving non-standard data structures collected through the use of recent technologies (Albert et al. 2016). Motion-tracking or remote sensor technologies, for instance, have made it possible to accumulate detailed information on player-level dynamics and athletes' characteristics (Liebermann et al. 2002), and large data archives for sports have become easily accessible even to non-experts. Computational advances have also determined a growing number of applications using sports data for measuring players' and teams' abilities, and decision-making within a game (see Albert et al. 2016, and reference therein). Apart from the value of the performance indicators, used to categorize athletes' and teams' performance, recent contributions focused on why and how some behaviors emerge in performance contexts (McGarry 2009) and in the ways in which performance interacts with personality traits (Laborde et al. 2020). Therefore, recent studies investigated which types of personality have more success in sport (Allen et al. 2013), widening the classical perspective focused on the measurement of athletes' abilities through tracking data. This led to the development of a branch of psychology_-sports psychology_-geared to study and explain performance and well-being of athletes in terms of their psychological traits. Researchers tried to define the personality of the successful athlete, comparing the personality test scores of lower performance athletes with those of higher performance ones, or exploring differences between professional and amateur athletes (Aidman 2007; Allen et al. 2011). Several studies investigated the association between personality and participation in organized sports, also accounting for gender differences (Allen et al. 2013; Malinauskas et al. 2014; Mckelvie et al. 2003; Paunonen 2003). Further analyses focused on athletes attending different sport types, showing differences in personality traits between team sport and individual sport athletes (Allen et al. 2011; Eagleton et al. 2007; Nia and Besharat 2010; Steca et al. 2018). Some contributions focused on interpersonal relationships in athlete-athlete and coach-athlete dyads and team functioning (Bell 2007; Jowett and Nezlek 2012; Rhind and Jowett 2011). These studies explored the role of dissimilarity in personality traits and the contribution of personality to team performance. Further approaches moved toward a deepening study of athletes' mental strategies and skills (Olmedilla et al. 2018), often based on the study of one of the main theoretical framework for analyzing personality in sport, that is the five-factor model (McCrae and Costa 2008). Although the huge number of mentioned researches, based on different statistical contents, fewer studies have focused on the relationships among personality traits, specific athletic skills and strategies to enhance performance. The present paper is framed in this line of 
research and aims to identify personality traits which can be successfully used to assess the performance of athletes engaged in individual sports. In the study, the performance is measured by means of an overall observable variable which allows overcoming the drawbacks of the measurements obtained with game statistics solely (Piedmont et al. 1999). Furthermore, the identification of psychosocial athletes' profile may update skill and training to improve the performance during competitions. The paper proposes a component-based structural equation modeling (component-based SEM) to analyze the relationships between some psychological constructs, measuring personality traits and mental skills, and a combination of indicators (composite), measuring sports performance. The main focus is on identifying personality traits and mental skills having the largest impact on sports performance. Rather than focusing only on objective behaviors, such an approach evaluates also variables not directly observable related to sport performance, such as cognition and affect, considering measurement error and measurement invariance, as well as the validity and reliability of the latent constructs. In the present paper, we consider data collected in 2019 for the STATSPO project (Statistical modeling and Data Analytics for Sports. Psychosocial aspects to assess the performance: the case of swimmers). The project was supported by University of Naples Federico II and Italian Swimming Federation ISF (Campania Regional Committee). Data consist of a small number of observations, due to the representative sample selected by ISF, along with a high number of both latent and corresponding manifest variables. This structure supports the choice of the component-based SEM as reference model for the proposed research as remarked in the next section. Specifically, the work is organized as follows. Section 2 presents methods for data collection and implementation in personality trait analysis. Section 3 provides a detailed description of the survey, the data and the constructs considered in the research. Section 4 presents the componentbased SEM, the reference methodology for analyzing the collected data. Results, separately for the measurement and the structural model, along with the evaluation of the model reliability, are reported in Sect. 5. Finally, a discussion on the main results and the conclusions with some further research developments to be explored are included in Sects. 6 and 7, respectively.

\section{Methodologies for personality traits analysis}

To collect data relevant to the quantitative measurement of constructs like attitudes and personality traits, multi-item scales are among the most popular measures used in questionnaires. More in detail, constructs are theoretical concepts not directly observable that can be inferred from a series of observable indicators (MacCorquodale and Meehl 1948). An example in our analysis is the athletes' personality, inferred by responses given to questions on behaviors and choices (Schweizer et al. 2020; Steca et al. 2018). According to the classical theory of measurement (Spearman 1904; Thurston 1947), the measurement of latent constructs almost always relies on the detection of a multivariate set of indicators of the construct itself. Since no single indicator can capture the overall theoretical meaning, classical 
theory exploits multiple measurements of the same latent concept. Many aptitude and personality tests, for instance, use questionnaires with a certain number of items which are combined to give a total score relative to some dimension of attitude or personality. When the phenomenon to be analyzed has a complex nature, as for the analysis of athletes' personality, several multi-item scales are jointly used to measure the different aspects of the phenomenon. In some cases, causal connections are also hypothesized among the different scales either making reference to underlying theories or setting some research hypotheses (Simon 1954).

Regarding the statistical methods in sport psychology research, the most popular included regression analysis, mediation and moderation analysis, analysis of variance, cluster analysis, and SEM (Biddle et al. 2001); in recent applications, also more complex methods such as latent class analysis, latent profile analysis, and growth mixture modeling are being to be used (Myers et al. 2018). Among them, SEM is the reference methodology to deal with latent constructs interconnected by a network of causal relationships.

SEM is a class of models aiming to analyze the relationships between a set of latent variables (LVs), measured through multiple manifest variables (MVs) (Bollen 1989). SEM combines the principles of factorial analysis (Spearman 1904) with those of path analysis (Wright 1918). In particular, factorial analysis relates the observed variables (items) to the respective constructs. This part of the model is named measurement or outer model. Instead, path analysis captures the structural connections relating constructs to each other. Structural or inner model is the name used to refer to this part of the model. Two main approaches have been proposed in the SEM literature. They are distinguished by the different estimation procedure (Henseler et al. 2009; Tenenhaus et al. 2005): covariance-based SEM (Jöreskog 1978) and component-based SEM (Wold 1982). Covariance-based SEM estimates the model parameters by minimizing the discrepancy between the empirical covariance matrix and the theoretical covariance matrix implied by the model. Instead, component-based SEM estimates the parameters after determining the construct scores as linear combinations of the corresponding observed variables while maximizing proximity to the connected constructs. Covariance-based SEM commonly exploits maximum likelihood estimation (Bollen 1989), whereas partial least squares path modeling (PLS-PM) is the usual choice for component-based SEM (Tenenhaus et al. 2005; Wold 1982).

In the last two decades, there has been a heated debate among supporters of the two approaches (Henseler et al. 2014; Rönkkö and Evermann 2013; Rönkkö et al. 2016). Very briefly, advocates of component-based SEM have outlined some particular advantages in terms of greater flexibility. Covariance-based SEM poses indeed distributional assumptions (continuous and normal data), and special requirements about the number of indicators per construct (generally three or more) and the sample size (generally several hundred, Iacobucci 2010). Recently, the debate focused on the type of constructs considered in the model. On the one side, the traditional constructs, typical of behavioral sciences, that assume a latent variable underlying the set of indicators; on the other side, the artificial constructs (emergent variables), typical of business and social sciences, that emerge from the indicators (Henseler 2017). Personality traits are an example of constructs of the first type, 
business process performance of the second type. The two types of constructs give rise to different models. In the first case, the hypothesis is that the manifest variables are explained by a common factor, that is the latent variable, and a unique random error. For this reason, indicators have to be strongly correlated since they are expression of the same underlying LV. In the case of emergent constructs, a linear combination of indicators provides the constructs. Therefore, the indicators of emerging variables are not required to be correlated with each other. Latent variables are also called reflective constructs, while emergent variables are also called formative constructs if they are intended to be formed and not caused by their indicators (Henseler 2020). The nature of the constructs, latent vs emergent, establishes the choice between covariance-based SEM and component-based SEM, the former being preferred when the model includes only latent variables, the latter when both latent and emergent variables are considered (Benitez et al. 2020; Henseler 2017).

As discussed above, component-based SEM is the proper choice to test models that simultaneously encompass latent and emergent variables as in the presented contribution.

\title{
3 Data
}

The presented survey aimed to investigate the relationships among sports performance, personality and athletes' mental skills. It involved a sample of young athletes enrolled in Italian Swimming Federation (Campania Regional Committee). A sample of 161 elite swimmers (from now on simply swimmers) was examined. Leading details on the sample are reported in Table 1.

Personality was assessed by using a list of 25 adjectives representative of the Big Five (B5) dimensions in the Italian lexical context (Barbaranelli et al. 2007; Caprara and Perugini 1994). The list consists of 5 adjectives for each of the five personality dimensions, namely Extraversion, Emotional stability, Openness, Agreeableness, and Conscientiousness. Participants were required to fill out the questionnaire indicating how appropriate each adjective is for describing themselves on a 5-point scale (not at all, slightly, moderately, quite a lot, at all). A previous study in sport

Table 1 Summary statistics concerning the characteristics of the 161 respondents of the survey

\author{
Gender \\ Female (39.18\%)-Male (60.82)\% \\ Education \\ Primary school diploma (77.14\%), High school diploma (20.82\%) \\ Bachelors degree or higher (2.04\%) \\ Style \\ Dolphin crawl (11.84\%), Freestyle stroke (40.82\%) \\ Backstroke (8.98\%), Breaststroke (15.92\%), None (22.44\%) \\ Age \\ Min (12)—Max (30)—Mean (15.42)—Standard deviation (3.20)
}


psychology conducted by Steca et al. (2018) also used this self-report measure to assess athletes' personality traits. Mental skills were evaluated using the sport performance psychological inventory (IPPS-48), made up of 48 items in which respondents state how often (from $1=$ never to $6=$ always) they describe their sporting experience (Robazza et al. 2009). IPPS-48 factors assess both cognitive and emotional aspects relevant to athletes' performance. This scale measures the following eight dimensions: Self-talk, Goal setting, Self-confidence, Emotional arousal control, Cognitive anxiety, Concentration disruption, Mental practice, and Race preparation. Finally, in this contribution, the observable variable related to performance $(P)$ takes into account win on competed races on a scale with five anchored options: 1 refers to no success in any competitions, 5 refers to success in all participated competitions. A detailed description of the scales and the analyzed traits/constructs is reported in Table 2, while Figs. 1 and 2 depict the divergent stacked bar charts for the B5 and the IPPS-48 dimensions, respectively. Each panel of the two figures refers to a given dimension, the corresponding items being on the vertical axis while the stacked bins represent the response rates associated with the different response modes. The bars in each panel are located with reference to the neutral point scale (moderately for the Big Five scale and 3.5 for the IPPS-48 scale). Therefore, in case the bar for a given item tends to lie in the right part of the plot, this denotes a percentage of respondents with points in the upper part of the correspondent scale. Inversely, in case the major part of the bar is located in the left part of the plot. Course, if respondents with low points balance respondents with high points, the

Table 2 Description of the scales and related constructs used in the analysis

Big Five assessment (B5)

It is composed by polytomous items equally divided among:

Extraversion (item 8, item 13, item 15, item 16, item 20)

Agreeableness (item 4, item 10, item 18, item 21, item 23)

Conscientiousness (item 7, item 12, item 19, item 17, item 22)

Emotional stability (item 1, item 3, item 5, item 9, item 25)

Openness (item 2, item 6, item 11, item 14, item 24)

Sport performance psychological inventory (IPPS-48)

It is composed by polytomous items divided by:

Self-talk (item 2 , item 10 , item 18 , item 26 , item 34 , item 42 )

Goal setting (item 5, item 13, item 21, item 29, item 37, item 45)

Self-confidence (item 4 , item 12 , item 20 , item 28 , item 36 , item 44 )

Emotional arousal control (item 8, item 16, item 24, item 32, item 40, item 48)

Cognitive anxiety (item 3 , item 11, item 19, item 27, item 35, item 43)

Concentration disruption (item 7 , item 15 , item 23, item 31, item 39, item 47)

Mental practice (item 6, item 14, item 22, item 30, item 38, item 46)

Race preparation (item 1, item 9, item 17, item 25, item 33, item 41)

Performance $(P)$

It is obtained by mixing two items related to competed races (win and participated in).

It is analyzed in an increasing value pointing at 5 for the best performance. 


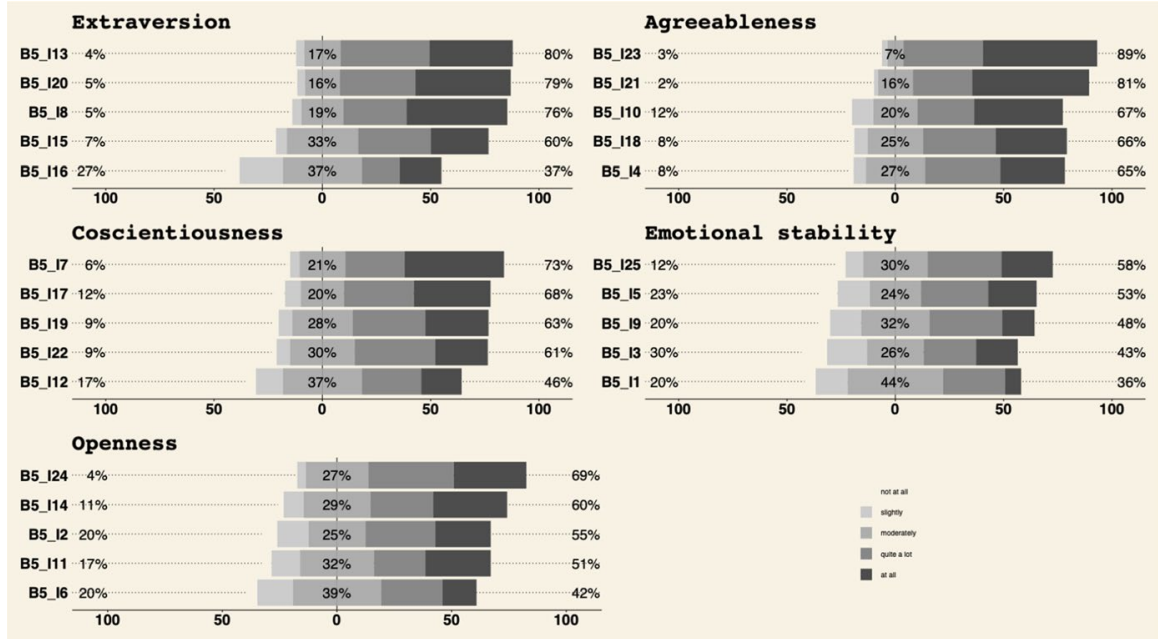

Fig. 1 Divergent stacked bar chart for the five dimensions of the B5 scale

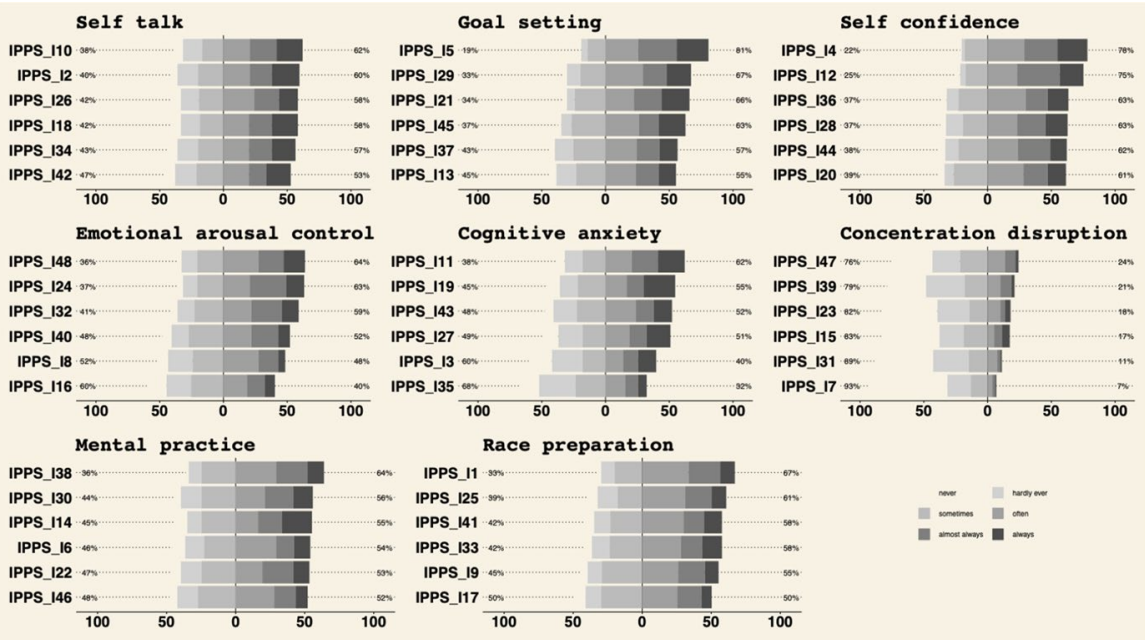

Fig. 2 Divergent stacked bar chart for the eight dimensions of the IPPS-48 scale

bar is centered around the neutral point scale, depicted by the solid vertical line in each panel. In addition, the bins composing a single bar (greyscale/different colors) express the rate of respondents for the given response mode. Segments of the same level in greyscale/same color are comparable across items and panels. Inspection of Fig. 1 shows that the majority of indicators has a negative asymmetric distribution, highlighting a marked agreement for all. With reference to each dimension of the B5 scale, this underlines the consistency of the items with respect to the construct they intend to measure. On the other hand, Fig. 2 points out discordant dimensions 
of the IPPS-48 scale. In fact, the dimensions representing Cognitive anxiety and Concentration disruption present positive asymmetric items, i.e., a disagreement of respondents on them. The same type of graph is used in Fig. 3 to report the observable variable related to performance. In this case, the chart presents a rather uniform distribution of athletes in terms of performance.

\section{Method}

SEM consists of two submodels, as already stated in Sect. 2 namely a measurement (outer) model, which describes the relationships between each construct and the corresponding indicators, and a structural (inner) model, which describes the relationships between the different constructs. In turn, the structural model is composed of as many structural equations as there are the dependent constructs in the model. A construct that assumes the role of dependent variable in at least one of the structural equations is defined endogenous, while a construct that assumes only the role of predictor is defined exogenous. In SEM framework, a graphical representation called path diagram is commonly used to represent in a visual way the variables and the relationships in the models: ellipses are used to represent latent variables, hexagons for emergent variables, squares for indicators, and arrows for relationships. The latter originate in the independent variables and point to the dependent variable and are used to depict both the relationships between variables and constructs (measurement model) and between the various constructs (structural model). The directionality of the arrows is defined by the theory that explains the analyzed phenomenon or by new research hypotheses. Note that most common SEMs are those in which relationships do not create cycles, i.e., feedback effects, but all flow in one direction. These models are called recursive, and we will refer to them throughout this work. Figure 4 depicts the path diagram proposed in this paper, limited to the inner model; indicators (measurement model) are not included for reasons of readability. From now on, we will refer to this model as the STATSPO model. As evident from the path diagram, the model proposed for the assessment of athletes' personality involves a high number of constructs, unlike what is typical in social and economic fields. This produces a dense network of relationships. The model assumes that both the exogenous constructs of the B5 scale and the endogenous ones of the IPPS-48 scale impact on the endogenous construct performance. Moreover, dependence relationships are also

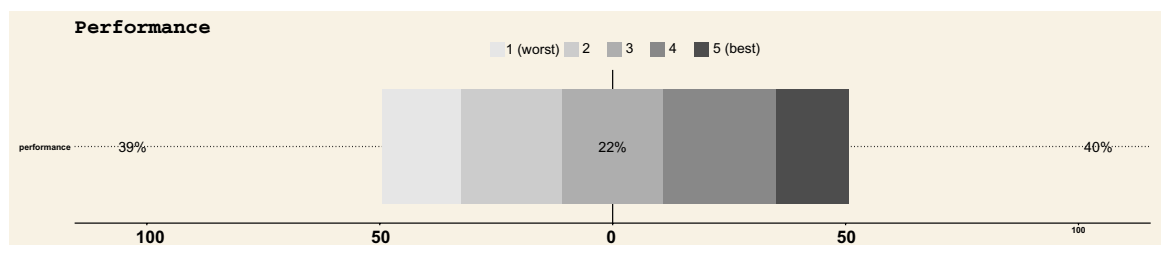

Fig. 3 Divergent stacked bar chart for the observable variable related to performance 


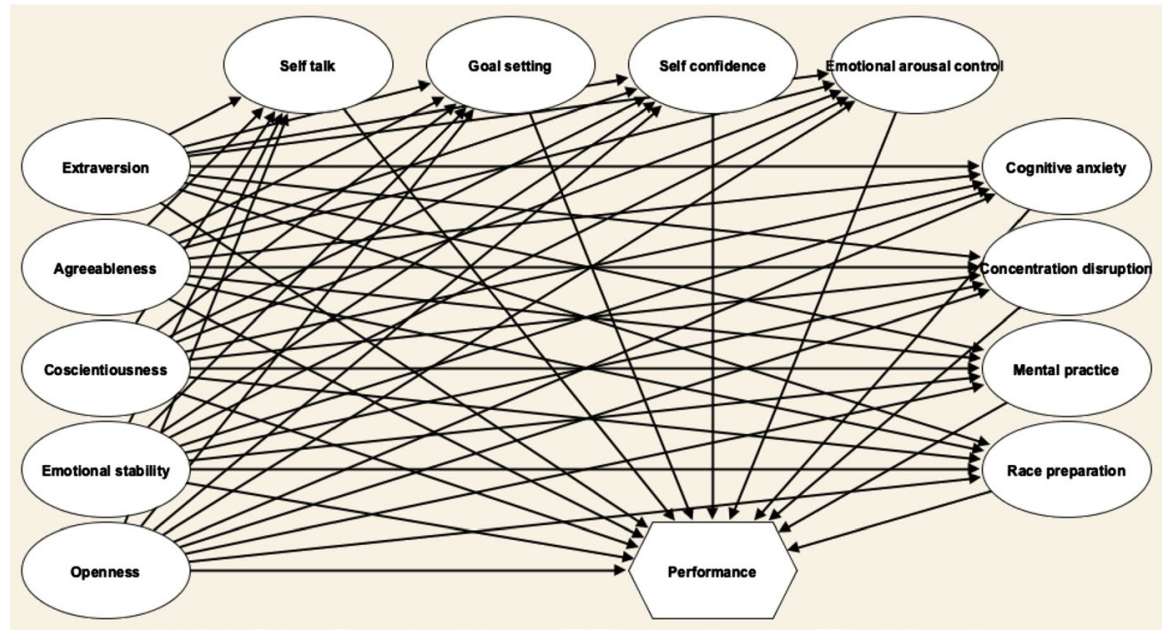

Fig. 4 Path diagram limited to the structural model for the assessment of athletes' personality (STATSPO model)

assumed between the two scales B5 and IPPS-48, with the latter assuming the role of mediator in the relationship between the B5 constructs and the P construct.

\subsection{The model}

The set of involved constructs can be formally represented by the vector

$$
\mathbf{Y}=\left[Y_{1}, \ldots, Y_{n}, \ldots Y_{n+1}, \ldots, Y_{n+m}\right]^{\prime},
$$

where, without loss of generality, the exogenous constructs are placed at the first $n$ positions, and the endogenous ones are positioned at the remaining $m$ positions. The indicators, observed on the $N$ statistical units and corresponding to the $j$-th construct, are denoted by $X_{j h}$, where $h=1, \ldots, p_{j}$, with $p_{j}$ denoting the number of indicators in the construct $j$. Below we use the index $i$ to refer to units $(i=1, \ldots, N)$.

Following the conventional notation, the structural model can be formulated as:

$$
Y_{j}=\sum_{k=1}^{j-1} \beta_{j k} Y_{k}+\zeta_{j}, j=n+1, \ldots, n+m,
$$

where $\beta$ denotes the so-called path coefficients, $\zeta$ the error term, and where each endogenous construct $Y_{j}$ can depend on one or more exogenous constructs $Y_{1}, \ldots, Y_{n}$, or on some preceding endogenous construct. This is because the present work focuses exclusively on recursive models. In addition, we assume the prediction specification hypothesis, that is $E\left(\zeta_{j} \mid Y_{1}, \ldots, Y_{j-1}\right)=0$ (Wold 1982).

According to the recent literature, different types of measurement model can be distinguished (Bollen and Bauldry 2011; Henseler 2017), and the selected candidate depends on the type of construct considered. In sciences, the constructs 
hypothesize the existence of a latent variable, and the reference model is the reflective measurement model:

$$
X_{j h}=\lambda_{j h} Y_{j}+\varepsilon_{j h}, j=1, \ldots, n+m,
$$

where each indicator is assumed to be a manifestation of a common factor $Y_{j}$ with an error term $\varepsilon_{j h}$. The parameter $\lambda_{j h}$ denotes the loading associated with the $h$-th manifest variable in the $j$-th construct. Also, in this model the prediction specification hypothesis is required, i.e., $E\left(\varepsilon_{j h} \mid X_{j 1}, \ldots, X_{j p_{j}}\right)=0$. Alternatively, when the construct does not assume any latent variable but corresponds to a mixture of elements without any kind of causal relationship, then the composite measurement model is the choice:

$$
Y_{j}=\sum_{h=1}^{p_{j}} \pi_{j h} X_{j h}, j=1, \ldots, n+m .
$$

Here, the $Y_{j}$ construct is composed as a linear combination of the $X_{j h}$ indicators with weights $\pi_{j h}$.

The STATSPO model represented in Fig. 4 includes both latent and emergent variables. The B5 and IPPS-48 scales measure the personality and mental characteristics of athletes and are therefore operationalized by reflective measurement model (3). In contrast, the performance is composed by a single item measuring win on competed races, and the composite measurement model (4) is employed.

\subsection{The algorithm}

Component-based SEM commonly exploits the PLS-PM algorithm as estimation method (Wold 1975, 1982). From hereinafter, the indicators are assumed to be centered. The algorithm starts with an initial phase where the weights for the scores of the constructs are obtained through an iterative procedure. The algorithm estimates then the parameters of the structural model (path coefficients) and of the measurement model (weights and loadings) (Lohomöller 1989). The main idea of PLS-PM is to obtain two alternative estimates of scores associated with each construct. One takes into account the measurement model (outer), and one takes into account the structural relationships (inner). In the first step, each construct is calculated as a linear combination of its own centered indicators using a set of arbitrary weights $w_{j 1}, \ldots, w_{j p_{j}}$ summing to 1 :

$$
\hat{Y}_{j}=\sum_{h=1}^{p_{j}} w_{j h} X_{j h} .
$$

The first outer estimate of the construct scores is obtained. Then, the first inner estimate of each construct is obtained as a normalized linear combination of the outer estimations of the connected constructs: 


$$
\hat{Z}_{j}=\sum_{k=1}^{n+m} \tau_{j k} \hat{Y}_{k}
$$

where the weights $\tau_{j k}$ can be defined according to different weighting scheme (see Lohomöller 1989 for more details). At this point, the algorithm updates the weights on the basis of two different modes, defined mode A and mode B:

mode A The weights are obtained through the simple regression of each indicator on the inner estimate of the corresponding construct.

mode B The weights correspond instead to the multiple regression coefficients of the inner estimate of the construct on the corresponding set of indicators.

The choice of the mode is strictly related to the nature of the measurement model: Mode A is more appropriate for a reflective model, i.e., for latent variables (Eq. 3), Mode B for a composite model, i.e., for emergent variables (Eq. 4). Once the weights have been updated, the algorithm iterates through the previous steps until the convergence criterion is satisfied:

$$
\left[\sum_{j} \sum_{h}\left(w_{i h}^{(s)}-w_{j h}^{(s-1)}\right)^{2}\right]^{1 / 2} \leq \varepsilon,
$$

where $\varepsilon$ is an appropriately chosen positive convergence tolerance value. After convergence, the final weights $w_{i h}^{s}$ are used to estimate the construct scores as a linear combination of the indicators:

$$
\hat{y}_{j i}=\sum_{h=1}^{p_{j}} w_{j h}^{(s)} x_{j h i} .
$$

The final scores are used to obtain the least squares estimate of the structural coefficients $\left(\beta_{j k}\right)$ according to Eq. 2 , and those of the measurement model $\left(\lambda_{j h}\right.$ and $\left.\pi_{j h}\right)$ according to Eqs. 3 and 4.

Note that in principle PLS-PM estimates composites and not common factors, so the scores obtained for the latent variables contain measurement errors. To overcome this issue, a variant called consistent PLS-PM (PLSc) (Dijkstra and Henseler $2015 b$ ) has been proposed to estimate reflective measurement model. However, the new approach could lead to not admissible solutions. This concerns the so-called Heywood cases (Krijnen et al. 1998), which occur when one or more variances implied by the model are negative. The small sample size is one of the causes related to the occurrence of Heywood cases. The STATSPO model, as previously described, has a very complex structure, with many constructs and a small sample size. The use of the PLSc is therefore not possible as some not admissible solutions are obtained. Therefore, we will consider Mode A to estimate the B5 and the IPPS-48 constructs. Although Mode A does not consistently estimate reflective measurement model, it provides weights that are proportional to the true correlations between the indicators and their common factor (Dijkstra and Henseler 2015a). 


\subsection{Model assessment}

The PLS-PM is generally validated separately for the measurement and the structural model using a sequential approach: once the assessment of the measurement model is satisfactory, it is possible to move on to the structural one. The assessment phase follows different tracks for reflective models and composite models. The reflective measurement model assumes a latent variable responsible for the correlation structure among the indicators, and several are the aspects to be verified; among them:

- Composite reliability: it checks the amount of random error contained in the construct scores, which is expected to be limited. The indicator $\rho_{a}$ (Dijkstra and Henseler 2015b) is a valid measure for PLS-PM. A reasonable threshold is the value of 0.707 , which indicates that more than $50 \%$ of the variance in the construct scores is explained by the corresponding latent variable.

- Convergent validity: it represents the amount of the indicators' variance explained by the latent variable. It is measured by the average variance extracted (AVE) index. A value greater than 0.5 is considered acceptable because it would mean that more than half of this variability is explained by the latent variable (Bagozzi and Yi 1988).

- Indicators reliability: it measures the amount of variance presented in latent variable in terms of the contribution of each indicator. The loadings are good candidates to measure this issue (Hair et al. 2010). Since loadings in PLS-PM are standardized, a value higher than 0.707 indicates that more than $50 \%$ of the indicator variance is explained by the corresponding latent variable. It should be mentioned that slightly lower values are not a concern as long as the construct validity and reliability are assured.

- Discriminant validity: it allows differentiation between the different aspects measured by latent variables. It can be measured through the heterotraitmonotrait ratio of correlations (HTMT) criterion (Henseler et al. 2015). A value lower than 0.85 indicates a good discriminant validity.

With respect to the composite measurement model, there are no stringent constraints on the correlations between indicators. The only aspects to be evaluated are the sign, size, and significance of the weights. It is also necessary to check for a possible multicollinearity among the indicators. In a composite model, weights are crucial as they determine the construct's scores, just like a weighted sum of their indicators (see Eq. 4). Furthermore, since they are obtained through a multiple regression with the construct scores as the dependent variable and the indicators as the independent variables, multicollinearity must be checked. High levels of collinearity could produce unexpected signs of the coefficients or large confidence intervals. Furthermore, to determine if the indicators really contribute to compose the construct, it is necessary to test that they are significantly different from zero.

With respect to the structural model, the assessment is similar to that of any regression model. Therefore the sign, size, and significance of the coefficients must be evaluated and tested. In case of mediator variables, indirect and total effects have 
to be considered. The total effects correspond to the sum of the indirect and direct effects, where the latter are expressed by the path coefficients. Furthermore, the $R^{2}$ index allows to evaluate the amount of variability of each endogenous construct explained by its predictor constructs. The $Q^{2}$ index (Chin 2010; Hair et al. 2016) is a further measure of the predictive relevance of the model. It measures how accurately the model predicts the omitted data points of indicators in reflective measurement models of endogenous constructs and single-item endogenous constructs (the procedure does not apply for composite models). Values of $Q^{2}$ greater than zero indicate highly predictive model for a specific construct, whereas values less than zero represent a lack of predictive relevance. Finally, for the significant effects, it may be useful to measure their effect size $f^{2}=\frac{R^{2}}{1-R^{2}}$. Values of $f^{2}$ greater than $0.35,0.15$, and 0.02 indicate strong, moderate and weak effects, respectively (Cohen 1988).

It is worth noting that all statistical inference in PLS-PM is based on bootstrap techniques, and in particular on percentile bootstrap confidence intervals (AguirreUrreta and Ronkko 2018). Recent developments propose a bootstrap-based test for the overall model fit (Dijkstra and Henseler 2015b; Henseler 2020; Henseler and Schuberth 2020). The null hypothesis is that the model fits perfectly, i.e., the variance-covariance matrix $\hat{\boldsymbol{\Sigma}}$ implied by the SEM does not differ from the observed variables' population variance-covariance matrix $\boldsymbol{\Sigma}$. Since the latter is typically not available, the empirical variance-covariance matrix $\mathbf{S}$ of the observed variables is considered.

The discrepancy between the two matrices is measured using the squared Euclidean distance:

$$
d_{\mathrm{ULS}}=\frac{1}{2} \operatorname{trace}(\mathbf{S}-\hat{\mathbf{\Sigma}})^{2} .
$$

An alternative measure exploits the geodesic discrepancy:

$$
d_{G}=\frac{1}{2} \sum_{k=1}^{P}\left(\log \left(\varphi_{k}\right)\right)^{2},
$$

where $\varphi_{k}$ is the $k$ th eigenvalue of $\mathbf{S}^{-1} \hat{\boldsymbol{\Sigma}}$ and $P$ is the total number of indicators in the model. A discrepancy value larger than the $95 \%$ (or $99 \%$ ) quantile of the corresponding reference distribution HI95 (or HI99) leads to rejection of the null hypothesis. The evaluation of the overall model fit of a saturated model, i.e., a model in which all constructs are allowed to be freely correlated, is used to assess the measurement and composite models' validity. Moreover, the standardized root mean squared residual (SRMR) is the reference measure of approximate model fit. A SRMR value smaller than 0.080 indicates an acceptable model fit (Henseler et al. 2015).

\section{Results for STATSPO data}

The following subsections report the PLS-PM results, first for the measurement model, and then for the structural model. In particular, the measures of validity of the latent constructs for the measurement model are reported in Sect. 5.1, while for 
Table 3 Evaluation of the overall fit of the saturated model

Table 4 Reliability analysis

\begin{tabular}{lrrr}
\hline & \multicolumn{1}{c}{ Value } & \multicolumn{1}{c}{ HI95 } & \multicolumn{1}{c}{ HI99 } \\
\hline SRMR & 0.076 & 0.064 & 0.067 \\
$d_{\mathrm{ULS}}$ & 15.857 & 11.316 & 12.294 \\
$d_{G}$ & 6.004 & 8.697 & 10.066 \\
\hline
\end{tabular}

\begin{tabular}{llll}
\hline Constructs & Items & AVE & $\rho_{A}$ \\
\hline Extraversion & 5 & 0.538 & 0.825 \\
Agreeableness & 5 & 0.526 & 0.826 \\
Conscientiousness & 5 & 0.517 & 0.841 \\
Emotional stability & 5 & 0.529 & 0.795 \\
Openness & 5 & 0.498 & 0.760 \\
Self-talk & 6 & 0.773 & 0.947 \\
Goal setting & 6 & 0.711 & 0.922 \\
Self-confidence & 6 & 0.705 & 0.921 \\
Emotional arousal control & 6 & 0.529 & 0.827 \\
Cognitive anxiety & 6 & 0.651 & 0.927 \\
Concentration disruption & 6 & 0.492 & 0.846 \\
Mental practice & 6 & 0.532 & 0.833 \\
Race preparation & 6 & 0.634 & 0.898 \\
\hline
\end{tabular}

the structural model tests for the hypothesized relationship among constructs are provided in Sect. 5.2.

Statistical analysis was carried out using R version 4.0.2 (R Core Team 2020), the semPLS (Monecke and Leisch 2012) and the cSEM (Rademaker and Schuberth 2020) packages. Additional custom R routines were used for creating specific graphs to display the different outputs.

\subsection{Measurement model results}

The assessment of the measurement model starts with the evaluation of the overall fit of the model with the saturated structural model. Table 3 reports three discrepancy measures and both the $95 \%$ and $99 \%$ quantiles of their corresponding reference distributions. Only the $d_{G}$ discrepancy measure is below the $95 \%$ quantile of the reference distribution (HI95), thus providing empirical evidence for the latent variables and the emergent variable inside the model. Moreover, the SRMR is below the suggested threshold of 0.080 (Henseler et al. (2014), indicating acceptable model fit.

The quality of the reflective measurement model is then assessed through several measures aimed to evaluate reliability, convergent validity, and discriminant validity. Table 4 shows the average variance extracted (AVE) and the Dijkstra-Henseler's rho $\left(\rho_{A}\right)$. The constructs and the corresponding numbers of items are reported on 
Table 5 Discriminant validity (HTMT)

\begin{tabular}{lllllllllllll}
\hline Construct & Extr & Agre & Cosc & Emot & Open & Self-T & Goal & Self-C & Arou & Cogn & Conc & Ment \\
\hline Agre & 0.455 & & & & & & & & & & & \\
Cosc & 0.503 & 0.662 & & & & & & & & & & \\
Emot & 0.533 & 0.359 & 0.399 & & & & & & & & & \\
Open & 0.744 & 0.548 & 0.396 & 0.410 & & & & & & & & \\
Self-T & 0.330 & 0.356 & 0.144 & 0.220 & 0.378 & & & & & & & \\
Goal & 0.603 & 0.278 & 0.274 & 0.319 & 0.403 & 0.493 & & & & & & \\
Self-C & 0.716 & 0.298 & 0.207 & 0.593 & 0.461 & 0.469 & 0.738 & & & & & \\
Arou & 0.525 & 0.226 & 0.210 & 0.701 & 0.486 & 0.307 & 0.520 & 0.778 & & & & \\
Cogn & 0.000 & 0.121 & 0.025 & 0.484 & 0.155 & 0.209 & 0.081 & 0.270 & 0.386 & & & \\
Conc & 0.344 & 0.134 & 0.308 & 0.329 & 0.014 & 0.067 & 0.308 & 0.407 & 0.186 & 0.327 & & \\
Ment & 0.372 & 0.263 & 0.364 & 0.339 & 0.359 & 0.463 & 0.656 & 0.421 & 0.331 & 0.080 & 0.070 & \\
Race & 0.470 & 0.181 & 0.201 & 0.193 & 0.363 & 0.516 & 0.753 & 0.600 & 0.499 & 0.015 & 0.150 & 0.653 \\
\hline
\end{tabular}

the first two columns of the table. The value of $\rho_{A}$ is greater than 0.70 for all latent variables, pointing at good internal reliability. The reflective measurement model also meets convergent validity, as indicated by the values of AVE. For all latent variables, indeed, AVE value is greater or close to 0.50 .

Indicator reliability can be assessed through Fig. 5 that depicts the results for the loadings: each panel corresponds to a block of the measurement model, the indicators are reported on the vertical axis, the values of the loadings on the horizontal axis. In each panel, the indicators are sorted in decreasing order according to

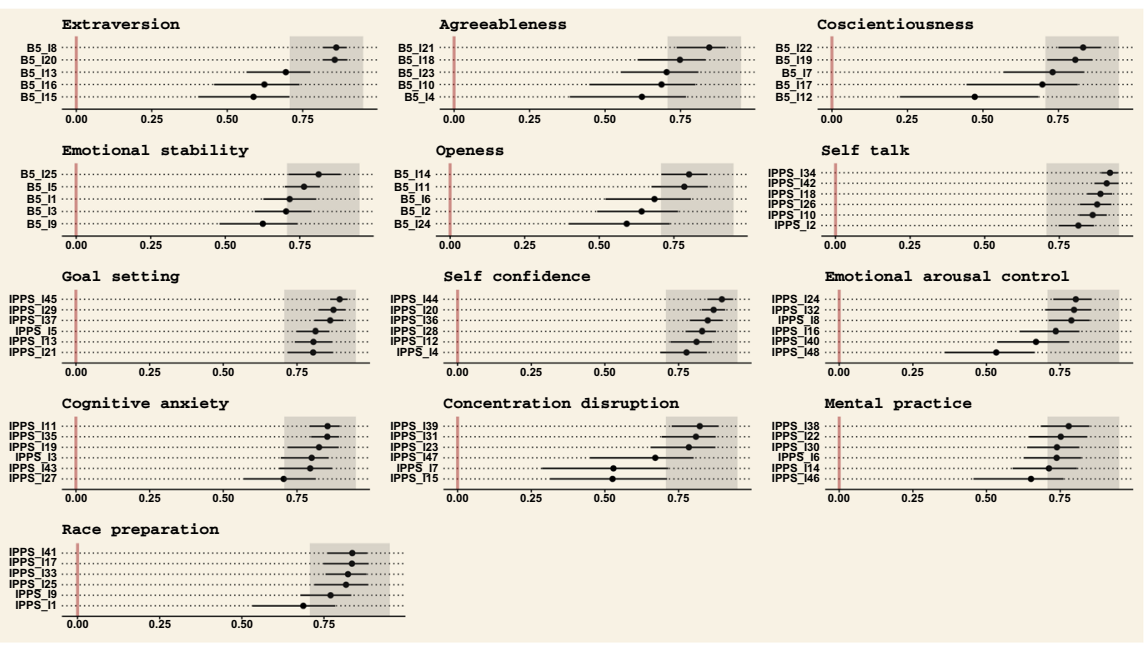

Fig. 5 Loadings (points) for the several constructs (panels) of the reflective measurement model. The indicators are reported on the vertical axis. In each panel, the indicators are sorted in decreasing order according to their values. Segments depict the $95 \%$ bootstrap confidence intervals. A vertical line is located at 0 , and a shaded area highlights the zone in which loadings are greater than 0.70 
their values. The points represent the estimates of the loadings, the segments the 95\% bootstrap confidence intervals. The vertical line placed at 0 in each panel highlights the significance of all the loadings. Finally, a shaded area is used to mark values greater than 0.70 . Figure 5 shows that all indicators are statistically significant. Moreover, all but B5_I12 report values greater than 0.50 (minimum threshold still considered acceptable, Hair et al. 2010).

Finally, we assess discriminant validity through the HTMT ratio. As shown in Table 5, all HTMT values are less than 0.85 , and then we can conclude that discriminant validity is satisfied for all constructs in the model.

In sum, results provide evidence for the reliability and validity of all the latent variables we considered.

As regards the assessment of the composite model, the multicollinearity, the weights, the loadings and their significance should be evaluated. However, the only emergent variable of the STATSPO model is the P construct, which is a single-indicator measurement (Diamantopoulos et al. 2012). In this case, the construct scores are identical to the standardized indicator values and the model assessment is then not required.

\subsection{Structural model results}

The evaluation of the structural model starts from the analysis of the overall fit of the estimated model, shown in Table 6 . The $d_{G}$ discrepancy value is below its corresponding HI95 value, indicating that the estimated model is not rejected at a 5\% significance level.

The results for the path coefficient estimates, their significance, and the coefficient of determination $\left(R^{2}\right)$ are summarized in Fig. 6. The figure follows the same style of the previous representation of the loadings: each panel refers to an endogenous construct, and the predictor constructs are on the vertical axis, sorted in decreasing order according with their values. The points depict the path coefficients, and the segments the correspondent $95 \%$ bootstrap confidence intervals (CIs). Lighter segments/points, crossing the vertical lines at 0 are not statistically significant, darker segments correspond to significant coefficients. The values of $R^{2}$ are reported in the subtitle of each panel.

As we expected, personality traits are related to athletes' mental skills. In particular, the Extraversion dimension affects Goal setting ( $\beta=0.44,95 \% \mathrm{CI}=0.22-0.56)$, Self-confidence $(\beta=0.50,95 \% \mathrm{CI}=0.35-0.65)$, and Race preparation $(\beta=0.31$, $95 \% \mathrm{CI}=0.06-0.46)$ in a positive way and the Concentration disruption $(\beta=-0.32$, $95 \% \mathrm{CI}=-0.52$ to -0.12 ) in a negative way. On the other hand, Emotional stability

Table 6 Evaluation of the overall fit of the estimated model

\begin{tabular}{lrrr}
\hline & Value & \multicolumn{1}{c}{ HI95 } & \multicolumn{1}{c}{ HI99 } \\
\hline SRMR & 0.117 & 0.072 & 0.074 \\
$d_{\text {ULS }}$ & 38.200 & 14.191 & 15.318 \\
$d_{G}$ & 6.553 & 8.728 & 10.099 \\
\hline
\end{tabular}



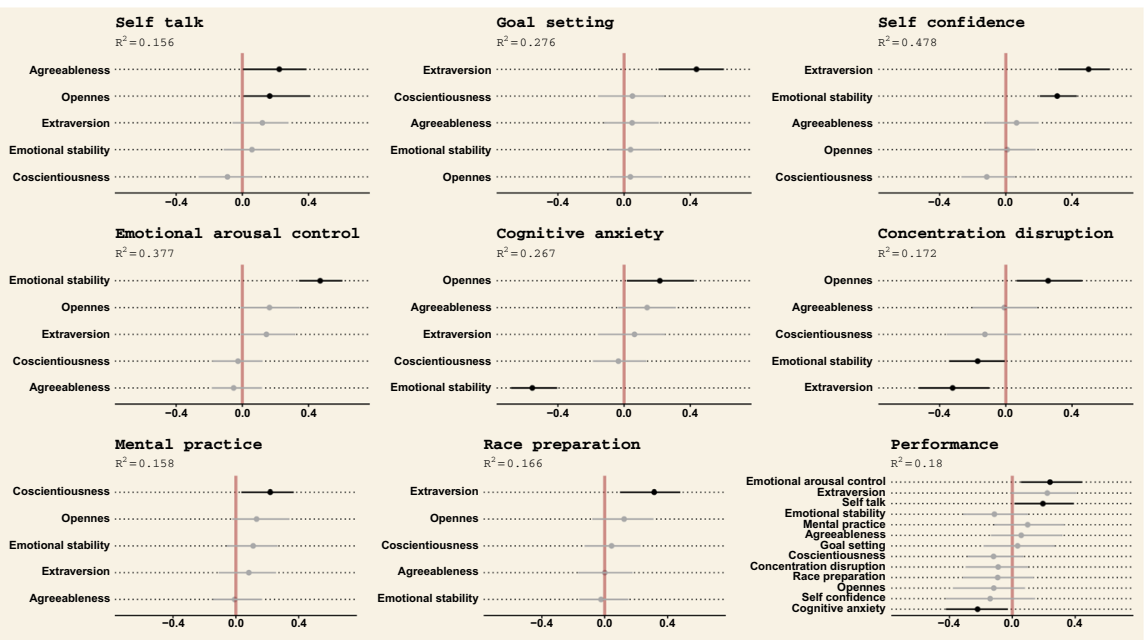

Fig. 6 Path coefficients (points) for the several endogenous constructs (panels) of the structural model. Segments depict the $95 \%$ bootstrap confidence intervals. The vertical lines located at 0 in each panel allow to visually catch the significance of the path coefficients: lighter segments correspond to nonsignificant path, darker segments to significant paths. The values of $R^{2}$ are reported in the subtitle of each panel

has a significant positive effect on Self-confidence $(\beta=0.31,95 \% \mathrm{CI}=0.20-0.43)$ and Emotional arousal control $(\beta=0.47,95 \% \mathrm{CI}=0.33-0.60)$, and a negative impact on Cognitive anxiety $(\beta=-0.55,95 \% \mathrm{CI}=-0.70$ to -0.40$)$ and Concentration disruption $(\beta=-0.17,95 \% \mathrm{CI}=-0.40$ to -0.02$)$. Openness affects more mental skills: Self-talk $(\beta=0.16,95 \% \mathrm{CI}=0.02-0.40)$, Cognitive anxiety $(\beta=0.22,95 \% \mathrm{CI}=0.01-0.39)$, and Concentration disruption $(\beta=0.25,95 \% \mathrm{CI}$ $=0.05-0.42)$. Finally, Conscientiousness and Agreeableness have a less widespread effect: the former is only related to Mental practice $(\beta=0.22,95 \% \mathrm{CI}=0.08-0.38)$, whereas the latter to Self-talk $(\beta=0.22,95 \% \mathrm{CI}=0.03-0.41)$. The values of $R^{2}$ for the IPPS-48 dimensions are reported in the subtitles of each panel of Fig. 6. They turn out to be good, ranging from 0.158 to 0.478 , especially for Self-confidence $\left(R^{2}=0.48\right)$, Emotional aurousal control $\left(R^{2}=0.38\right)$, Goal setting $\left(R^{2}=0.28\right)$, and Cognitive anxiety $\left(R^{2}=0.27\right)$.

Regarding the relationship between mental skills and personality traits on performance, Self-talk, Emotional arousal control, and Cognitive anxiety affect swimmer's performance, accounting for $18 \%$ of the variance $\left(R^{2}=0.18\right)$. In particular, Self-talk and Emotional arousal control have a positive effect on the performance $(\beta=0.23,95 \% \mathrm{CI}=0.03-0.44$, and $\beta=0.29,95 \% \mathrm{CI}=$ 0.07-0.54, respectively), whereas a negative effect is found for Cognitive anxiety ( $\beta=-0.23,95 \% \mathrm{CI}=-0.44$ to -0.03 ). Contrary to our hypotheses, personality traits do not significantly affect performance directly (see results related to path coefficient). However, indirect effects (mediated by mental skills) and the total ones (direct and indirect) can be evaluated. This decomposition of the effects is depicted in Fig. 7: the dimensions are reported on the vertical axis in decreasing 


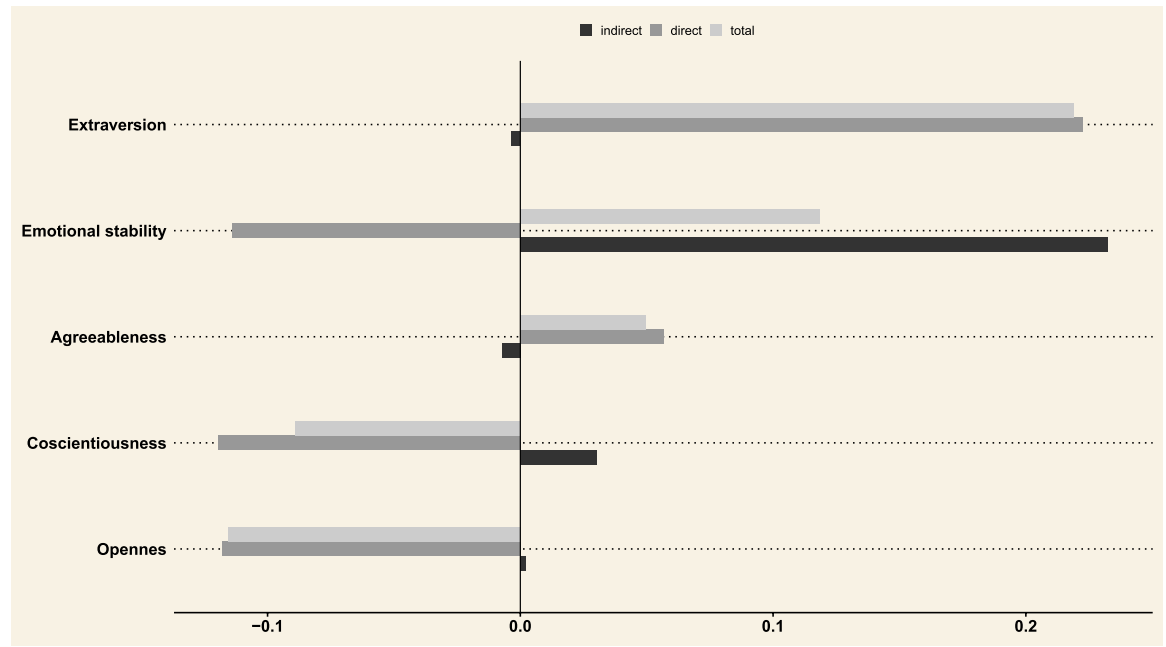

Fig. 7 Decomposition of the effects on Performance for the personality traits dimensions. The top bars associated with each dimension (vertical axis) depict the total effects, the direct and indirect effects are represented using the middle bars and bottom bars, respectively. The dimensions are sorted in decreasing order according to their total effects on performance

order according to the total effects (top bars for each dimension), the middle bars and the bottom bars represent the direct and indirect effect, respectively. Results in Fig. 7 show a relevant indirect effect for the Emotional stability trait (indirect effect $=0.25, \mathrm{CI}=0.12-0.41)$. In addition, the effect size of the significant path coefficients ranges from 0.02 (Openess $\longrightarrow$ Self-talk) to 0.31 (Emotional stability $\longrightarrow$ Cognitive anxiety), and thus, it is small-to-medium, according to the Cohen's category $\left(f^{2}\right.$ index). Detailed information on the $f^{2}$ values for all constructs is given in the supplementary material. The significance of the indirect effect highlights the role of mediator of mental skills in the relationship between Emotional stability and Performance. It is a full mediation (Henseler and Schuberth 2020; Nitzl et al. 2016) since the direct effect of Emotional stability is not significant (as evidenced by the confidence interval in Fig. 6), while the indirect one is. This means that mental skills absorb the direct relationship to change its direction, as evidenced by the positive sign of the total effect. The results in Table 7 report the decomposition of the total effect into direct and indirect effects and the decomposition of the indirect effect into the various components (partial indirect effects) relating to each of the mental skills. It is worth noting that the indirect effect through Emotional arousal control and Cognitive anxiety is substantial, implying that they totally mediate the effect of Emotional stability on Performance.

The $Q^{2}$ index was calculated to measure the model's predictive relevance for the indicators of the reflective measurement models of the endogenous constructs. The $Q^{2}$ values are all greater than zero (Cognitive anxiety $=0.127$, Concentration disruption $=0.048$, Emotional arousal control $=0.152$, Goal setting $=0.144$, Mental practice $=0.047$, Race preparation $=0.055$, Self-confidence $=0.299$, Self-talk $=0.056$ ), thus highlighting a predictive relevance for all the reflective constructs examined. 
Table 7 Effect estimates of Emotional stability on Performance

\begin{tabular}{lr}
\hline Effect & Estimate \\
\hline Direct & -0.137 \\
Emotional stability $>$ Performance $(a)$ & 0.014 \\
Indirect & 0.002 \\
Emotional stability $>$ Self-talk $>$ Performance $(b 1)$ & 0.039 \\
Emotional stability $>$ Goal setting $>$ Performance $(b 2)$ & 0.137 \\
Emotional stability $>$ Self-confidence $>$ Performance $(b 3)$ & 0.126 \\
Emotional stability $>$ Emotional arousal control $>$ Performance $(b 4)$ & 0.004 \\
Emotional stability $>$ Cognitive anxiety $>$ Performance $(b 5)$ & 0.005 \\
Emotional stability $>$ Concentration disruption $>$ Performance $(b 6)$ & 0.003 \\
Emotional stability $>$ Mental practice $>$ Performance $(b 7)$ & 0.252 \\
Emotional stability $>$ Race preparation $>$ Performance $(b 8)$ & \\
Emotional stability $>$ Performance $(c=b 1+b 2+b 3+b 4+b 5+b 6+b 7+b 8)$ & 0.115 \\
Total & \\
Emotional stability $>$ Performance $(a+c)$ &
\end{tabular}

\section{Discussion}

The study examined by component-based SEM methodology how the personality traits mostly affect swimmers' mental skills and, in turn, the effect of mental skills on their performance.

Our results show that Self-confidence and Emotional arousal control are the skills strongly related to Big Five personality traits. As reported in Bellou et al. (2018), the lack of Emotional stability (also defined as neuroticism) generally causes low self-confidence levels. In our specific context, this means that the tendency to be emotionally reactive and insecure lead swimmers to feel not being up to gain expertise, achieve goals, and express their potential. On the other hand, experiencing positive emotions (being extravert) positively affects the swimmers' confidence in their skills. Emotional arousal control is greatly influenced only by the Emotional stability personality trait. Therefore, swimmers who are able to manage stress and emotions also succeed in controlling competition stress and anxiety and channeling the concentration and energy on the performance. This finding is in agreement with the results in Petito et al. (2016). Regarding the other two mental skills related to emotional aspects, namely Cognitive anxiety and Concentration disruption, we found that both are related to the personality traits of Emotional stability and Openness. In particular, openness to experience can be defined as the tendency to seek new experiences: swimmers who enjoy new and exciting tasks tend to report a higher cognitive anxiety level and concentration disruption. As far as we know, these relationships have not been clearly explored in the literature. We can speculate that being fascinated by many different stimuli could not allow athletes to focus their attention on sporting goals, generating more anxiety for their performance and concentration problems. Conversely, swimmers with a low score on Emotional stability, and with a high level of apprehensiveness and predisposition to anxiety, tend to experience 
more cognitive anxiety and worry before and during competitions, and a more impaired concentration. These results are in line with those reported in Allen et al. (2013) and Petito et al. (2016). Concentration disruption is also influenced by Extraversion. This appears to be in contrast with the other evidence in sport psychology research (Allen et al. 2020). Indeed, in our sample, extraverted swimmers present a higher level of concentration. However, a study conducted by Kaiseler et al. (2019) showed that extraversion negatively predicts the use of distraction-oriented coping in sport. In other words, this means that when extraverted athletes cope with stressful situations (i.e., what we mean by coping strategy), they are less likely to shift their attention on non-sport-related aspects causing mental distraction.

Compared to emotional aspects, mental skills involving cognitive aspects are less influenced by personality traits. The frequency of inner dialogue recourse to instruct and motivate oneself, namely Self-talk (Van Raalte et al. 2016), is related to the personality traits of Agreeableness and Openness. In particular, swimmers with a more trusting and helpful way of thinking (Agreeableness) and an imaginative, creative, and flexible personality (Openness) are more prone to use self-talk to enhance their performance. These results are consistent with what was reported in Brinthaupt (2019) and Depape et al. (2006). In addition, Extraversion affects two cognitive aspects related to swimmer's mental skills: Goal setting and Race preparation. Being determined, resolute, dominant, and energetic increases the swimmer's ability to define adequate action plans and strategies to reach athletes' goals, practicing them during their training. Finally, swimmers who are more organized, hardworking, and responsible (i.e., Conscientious) tend to simulate reality: they mentally reproduce their movements (Mental practice) to improve and refine their abilities. Other works exploring the relationships between personality and mental skills for other sports report similar results (Budnik-Przybylska et al. 2019; Judge and Ilies 2002). Furthermore, results highlight the role of mediator of mental skills in the relationship between Emotional stability and Performance.

As regards the latter, swimmers involved in this study are heterogeneous: $39 \%$ did not participate in many competitions and did not often win, about $22 \%$ reported a moderate success, whereas $40 \%$ participated in many competitions and had good performances. Our study suggests that three of the considered mental skills are particularly important to have successful performances in swimmer competitions. Two skills involve emotional aspects (Self-confidence and Cognitive anxiety) and one cognitive practice (Self-talk). Firstly, self-talking allows swimmers to focus on the present moment, avoid distractions, acquire new skills, modify incorrect automatic movements, and consequently improve their performance. Secondly, negative expectations about performance and concern about the possibility of failure negatively impact the performance, lowering swimmers' possibility of success. Thirdly, swimmers able to manage stress and emotions channeling their energy on the performance reach also better results in very stressful competitions.

Finally, only indirect and positive effect of Emotional stability on Performance has been detected when mental skills were used as mediators between personality traits and performance. In such a case, no direct effect of personality on performance emerges from the research. The total effects suggest a high impact of Self-talk, Emotional arousal control, Cognitive anxiety, and Extraversion on 
swimmers' performance. We also highlighted the specific mental skills particularly related to participation and success in swimmer competitions. From a practical point of view, we retain that these findings could be really useful to design strategies and interventions both for coaches and swimmers to maximize the performance and well-being.

\section{Conclusion}

The interest in the role of personality in sport has been increasing in recent years. Several studies have pointed out the effect of personality traits on athletes' performance and success (see Allen et al. 2013; Allen and Laborde 2014; Steca et al. 2018 among the others). In contrast, fewer studies have focused the relation among personality traits and specific athletic behaviors, skills, and strategies to enhance performance. To fill this gap, our work provides evidence on what personality traits mostly affect swimmers' mental skills and, in turn, the effect of mental skills on their performance. The current study advances an important line of inquiry studying the interdependence of psycho-social aspects and performance of athletes and providing evidence for a very specific athlete's population (elite swimmers). Our sample's homogeneity, very uncommon in research on organized sports (Steca et al. (2018), allows us to provide findings on an athlete's category that has received little attention in the literature. Although this study addressed some relevant questions, it has its limitations. One limitation is that the data are about a sample of young swimmers; therefore, claims may arise on some specific questions concerning the personal sphere. It remains unclear whether the results are cyclically related and together are caused by such factors as individual difference characteristics and sociocultural variables, as well as other factors. Longitudinal and experimental research on different clusters could uncover these potential multi-layered variables. Another extension is about the possibility to consider further objective measures to evaluate the performance also with respect to the swimming style that may be considered in future studies. With reference to the last point, it would be interesting to investigate the role of coach and his/her contribution in objective and subjective performance-related outcomes and athletes' skills or well-being (e.g., win-loss record, personal bests, technique acquisition, competence, conflict). Finally, future research should extend the main findings in both other sports and contexts.

Supplementary Information The online version contains supplementary material available at https://oi. org/10.1007/s10182-021-00417-5.

Acknowledgements This research was carried out in the context of the project "Statistical Modelling and Data Analytics for Sports. Psychosocial aspects to assess the performance: the case of swimmers" (University of Naples Federico II- Italian Swimming Federation, Campania) and partially supported by Osservatorio Regionale delle Politiche Giovanili 2- POR CAMPANIA FSE 2014-2020-Cup Project: E64I19002390005. 
Funding Open access funding provided by Università degli Studi di Napoli Federico II within the CRUICARE Agreement.

Open Access This article is licensed under a Creative Commons Attribution 4.0 International License, which permits use, sharing, adaptation, distribution and reproduction in any medium or format, as long as you give appropriate credit to the original author(s) and the source, provide a link to the Creative Commons licence, and indicate if changes were made. The images or other third party material in this article are included in the article's Creative Commons licence, unless indicated otherwise in a credit line to the material. If material is not included in the article's Creative Commons licence and your intended use is not permitted by statutory regulation or exceeds the permitted use, you will need to obtain permission directly from the copyright holder. To view a copy of this licence, visit http://creativecommons.org/licen ses/by/4.0/.

\section{References}

Aguirre-Urreta, M., Rönkkö, M.: Statistical inference with PLSc using bootstrap confidence intervals. MIS Q. 42(3), 1001-1020 (2018)

Aidman, E.V.: Attribute-based selection for success: the role of personality attributes in long-term predictions of achievement in sport. J. Am. Board Sport Psychol. 3, 1-18 (2007)

Albert, J., Glickman, M.E., Swartz, T.B., Koning, R.H. (Eds.). Handbook of Statistical Methods and Analyses in Sports (1st ed.). Chapman and Hall/CRC (2016)

Allen, M.S., Greenlees, I., Jones, M.: An investigation of the five-factor model of personality and coping behaviour in sport. J. Sports Sci. 29(8), 841-850 (2011)

Allen, M.S., Greenlees, I., Jones, M.: Personality in sport: a comprehensive review. Int. Rev. Sport Exerc. Psychol. 6(1), 184-208 (2013)

Allen, M.S., Laborde, S.: The role of personality in sport and physical activity. Curr. Dir. Psychol. Sci. 23(6), 460-465 (2014)

Allen, M.S., Mison, E.A., Robson, D.A., Laborde, S.: Extraversion in sport: a scoping review. Int. Rev. Sport Exerc. Psychol. 23(6), 1-31 (2020)

Bagozzi, R.P., Yi, Y.: On the evaluation of structural equation models. J. Acad. Mark. Sci. 16(1), 74-94 (1988)

Barbaranelli, C., Caprara, G.V., Vecchione, M., Fraley, C.R.: Voters personality traits in presidential elections. Personal. Individ. Differ. 42(7), 1199-1208 (2007)

Bell, S.T.: Deep-level composition variables as predictors of team performance: a metaanalysis. J. Appl. Psychol. 92(3), 595-615 (2007)

Bellou, V., Stylos, N., Rahimi, R.: Predicting hotel attractiveness via personality traits of applicants. Int. J. Contemp. Hosp. Manag. 30(10), 3135-3155 (2018)

Benitez, J., Henseler, J., Castillo, A., Schuberth, F.: How to perform and report an impactful analysis using partial least squares: guidelines for confirmatory and explanatory IS research. Inf. Manag. 57(2), 103-168 (2020)

Biddle, S.J.H., Markland, D., Gilbourne, D., Chatzisarantis, N.L.D., Sparkes, A.C.: Research methods in sport and exercise psychology: quantitative and qualitative issues. J. Sports Sci. 19(10), 777-809 (2001)

Bollen, K.A.: Structural Equations with Latent Variables. Wiley, New York (1989)

Bollen, K.A., Bauldry, S.: Three Cs in measurement models: causal indicators, composite indicators, and covariates. Psychol. Methods 16(3), 265-284 (2011)

Brinthaupt, T.M.: Individual differences in self-talk frequency: social isolation and cognitive disruption. Front. Psychol. 10, 1088 (2019)

Budnik-Przybylska, D., Kaźmierczak, M., Przybylski, J.: Can personality factors and body esteem predict imagery ability in dancers? Sports 7(6), 131-168 (2019)

Caprara, G.V., Perugini, M.: Personality described by adjectives: the generalizability of the Big Five to the Italian lexical context. Eur. J. Pers. 8(5), 357-369 (1994)

Chin, W.W.: Bootstrap cross-validation indices for pls path model assessment. In: Esposito Vinzi, V., Chin, W.W., Henseler, J., Wang, H. (eds.) Handbook of Partial Least Squares, pp. 83-97. Springer, Berlin (2010) 
Cohen, J.: Statistical Power Analysis for the Behavioral Sciences. Lawrence Erlbaum, Mahwah, NJ (1988)

Costa, P.T., McCrae, R.R.: Revised NEO personality inventory and NEO five-factor inventory: professional manual. Psychological Assessment Resources, Odessa, FL (1992)

Depape, A.M.R., Hakim-Larson, J., Voelker, S., Page, S., Jackson, D.L.: Self-talk and emotional intelligence in university students. Can. J. Behav. Sci. 38(3), 250-260 (2006)

Diamantopoulos, A., Sarstedt, M., Fuchs, C., Wilczynski, P., Kaiser, S.: Guidelines for choosing between multi-item and single-item scales for construct measurement: a predictive validity perspective. J. Acad. Mark. Sci. 40(3), 434-449 (2012)

Dijkstra, T.K., Henseler, J.: Consistent and asymptotically normal PLS estimators for linear structural equations. Comput. Stat. Data Anal. 81, 10-23 (2015)

Dijkstra, T.K., Henseler, J.: Consistent partial least squares path modeling. MIS Q. 39(2), 297-316 (2015)

Eagleton, J.R., McKelvie, S.J., De Man, A.: Extraversion and neuroticism in team sport participants, individual sport participants, and nonparticipants. Percept. Mot. Skills 105(1), 265-275 (2007)

Hair, J.F., Black, W.C., Babin, B.J., Anderson, R.E.: Multivariate Data Analysis. Prentice Hall, Englewood Cliffs, NJ (2010)

Hair, J., Hult, G.T.M., Ringle, C., Sarstedt, M.A.: Primer on Partial Least Squares Structural Equation Modeling (PLS-SEM). Sage Publishing, Los Angeles, US-CA (2016)

Henseler, J., Ringle, C. M., Sinkovics, R.R.: The use of partial least squares path modeling in international marketing. In: New Challenges to International Marketing. Emerald Group Publishing Limited (2009)

Henseler, J., Dijkstra, T.K., Sarstedt, M., Ringle, C.M., Diamantopoulos, A., Straub, D.W., Calantone, R.J.: Common beliefs and reality about PLS comments on Rönkkö and Evermann. Org. Res. Methods 17(2), 182-209 (2014)

Henseler, J., Ringle, C.M., Sarstedt, M.: A new criterion for assessing discriminant validity in variancebased structural equation modeling. J. Acad. Mark. Sci. 43(1), 115-135 (2015)

Henseler, J.: Bridging design and behavioural research with variance-based structural equation modelling. J. Advert. 46(1), 178-192 (2017)

Henseler, J.: Composite-Based Structural Equation Modeling: Analyzing Latent and Emergent Variables. Guilford Publications, New York (2020)

Henseler, J., Schuberth, F.: Using confirmatory composite analysis to assess emergent variables in business research. J. Bus. Res. 120, 147-156 (2020)

Iacobucci, D.: Structural equations modeling: fit indices, sample size, and advanced topics. J. Consum. Psychol. 20(1), 90-98 (2010)

Jöreskog, K.G.: Structural analysis of covariance and correlation matrices. Psychometrika 43(4), 443477 (1978)

Jowett, S., Nezlek, J.: Relationship interdependence and satisfaction with important outcomes in coachathlete dyads. J. Soc. Pers. Relat. 29, 287-301 (2012)

Judge, T.A., Ilies, R.: Relationship of personality to performance motivation: a meta-analytic review. J. Appl. Psychol. 87(4), 797-807 (2002)

Kaiseler, M., Levy, A., Nicholls, A.R., Madigan, D.J.: The independent and interactive effects of the Big-Five personality dimensions upon dispositional coping and coping effectiveness in sport. Int. J. Sport Exerc. Psychol. 17(4), 410-426 (2019)

Krijnen, W.P., Dijkstra, T.K., Gill, R.D.: Conditions for factor (in)determinacy in factor analysis. Psychometrika 63(4), 359-367 (1998)

Laborde, S., Allen, M.S., Katschak, K., Mattonet, K., Lachner, N.: Trait personality in sport and exercise psychology: a mapping review and research agenda. Int. J. Sport Exerc. Psychol. 18(6), 701-716 (2020)

Liebermann, D.G., Katz, L., Hughes, M.D., Bartlett, R.M., McClements, J., Franks, I.M.: Advances in the application of information technology to sport performance. J. Sports Sci. 20(10), 755-769 (2002)

Lohomöller, J.: Latent Variable Path Modeling with Partial Least Squares. Physica-Verlag, Heildelberg (1989)

MacCorquodale, K., Meehl, P.E.: On a distinction between hypothetical constructs and intervening variables. Psychol. Rev. 55(2), 95-107 (1948)

Malinauskas, R., Dumciene, A., Mamkus, G., Venckunas, T.: Personality traits and exercise capacity in male athletes and non-athletes. Percept. Mot. Skills 118(1), 145-161 (2014) 
McCrae, R.R., Costa, P.T.: The five-factor theory of personality. In: John, O.P., Robins, R.W., Pervin, L.A. (eds.) Handbook of Personality: Theory and Research, pp. 159-181. Guilford Press, New York, NY (2008)

McGarry, T.: Applied and theoretical perspectives of performance analysis in sport: scientific issues and challenges. Int. J. Perform. Anal. Sport 9(1), 128-140 (2009)

Mckelvie, S.J., Lemieux, P., Stout, D.: Extraversion and neuroticism in contact athletes, no contact athletes and non-athletes: a research note. Athl. Insight Online J. Sport Psychol. 5(3), 19-27 (2003)

Monecke, A., Leisch, F.: semPLS: structural equation modeling using partial least squares. J. Stat. Softw. 48(3), 1-32 (2012)

Nia, M.E., Besharat, M.A.: Comparison of athletes personality characteristics in individual and team sports. Proc. Social Behav. Sci. 5, 808-812 (2010)

Nitzl, C., Roldan, J.L., Cepeda, G.: Mediation analysis in partial least squares path modeling: helping researchers discuss more sophisticated models. Ind. Manag. Data Syst. 116(9), 1849-1864 (2016)

Myers, N.D., Ntoumanis, N., Gunnell, K.E., Gucciardi, D.F., Lee, S.: A review of some emergent quantitative analyses in sport and exercise psychology. Int. Rev. Sport Exerc. Psychol. 11(1), 70-100 (2018)

Olmedilla, A., Torres-Luque, G., García-Mas, A., Rubio, V.J., Ducoing, E., Ortega, E.: Psychological profiling of triathlon and road cycling athletes. Front. Psychol. 9, 825 (2018)

Paunonen, S.V.: Big Five factors of personality and replicated predictions of behavior. J. Pers. Soc. Psychol. 84(2), 411-424 (2003)

Petito, A., Altamura, M., Iuso, S., Padalino, F.A., Sessa, F., D‘Andrea, G., Margaglione, M., Bellomo, A.: The relationship between personality traits, the 5HTT polymorphisms, and the occurrence of anxiety and depressive symptoms in elite athletes. PLoS One 11(6), e0156601 (2016)

Piedmont, R.L., Hill, D.C., Blanco, B.: Predicting athletic performance using the fivefactor model of personality. Personal. Individ. Differ. 27, 769-777 (1999)

R Core Team. R: A language and environment for statistical computing. R Foundation for Statistical Computing, Vienna, Austria. (2020) https://www.R-project.org/

Rademaker, M.E., Schuberth, F. cSEM: Composite-Based Structural Equation Modeling. Package version: 0.3.1, (2020) https://m-e-rademaker.github.io/cSEM/

Rhind, D.J.A., Jowett, S.: Working with coach-athlete relationships: their quality and maintenance. In: Mellalieu, S., Hanton, S. (eds.) Professional Practice in Sport Psychology: A Review, pp. 219-248. Routledge, London, UK (2011)

Robazza, C., Bortoli, L., Gramaccioni, G.: L‘inventario psicologico della prestazione sportiva (IPPS-48). Giornale italiano di psicologia dello sport 4, 14-20 (2009)

Rönkkö, M., Evermann, J.A.: Critical examination of common beliefs about partial least squares path modelling. Org. Res. Methods 16(3), 425-448 (2013)

Rönkkö, M., McIntosh, C.N., Antonakis, J., Edwards, J.R.: Partial least squares path modelling: time for some serious second thoughts. J. Oper. Manag. 47, 9-27 (2016)

Schweizer, G., Furley, P., Rost, N., Barth, K.: Reliable measurement in sport psychology: the case of performance outcome measures. Psychol. Sport Exerc. 48, 101663 (2020)

Simon, H.A.: Spurious correlation: a causal interpretation. J. Am. Stat. Assoc. 49(267), 467-479 (1954)

Spearman, C.: General Intelligence objectively determined and measured. Am. J. Psychol. 15(2), 201293 (1904)

Steca, P., Baretta, D., Greco, A., D‘Addario, M., Monzani, D.: Associations between personality, sports participation and athletic success: a comparison of Big Five in sporting and non-sporting adults. Personal. Individ. Differ. 121, 176-183 (2018)

Tenenhaus, M., Vinzi, V.E., Chatelin, Y.M., Lauro, C.: PLS path modeling. Comput. Stat. Data Anal. 48(1), 159-205 (2005)

Thurston, L.L.: Multiple Factor Analysis. University of Chicago Press, Chicago (1947)

Van Raalte, J.L., Vincent, A., Brewer, B.W.: Self-talk: review and sport-specific model. Psychol. Sport Exerc. 22, 139-148 (2016)

Wold, H.: Path models with latent variables: the non-linear iterative partial least squares (NIPALS) approach. In: Blalock, H.M., Aganbegian, A., Borodkin, F.M., Boudon, R., Capecchi, V. (eds.) Quantitative Sociology: Intentional Perspective on Mathematical and Statistical Modeling, pp. 307357. Accademic Press, New York (1975)

Wold, H.: Soft modeling: the basic design and some extensions. In: Jöreskog, K.G., Wold, H. (eds.) Systems under Indirect Observation, pp. 1-54. North-Holland, Amsterdam (1982) 
Woodman, T., Zourbanos, N., Hardy, L., Beattie, S., McQuillan, A.: Do performance strategies moderate the relationship between personality and training behaviors? An exploratory study. J. Appl. Sport Psychol. 22(2), 183-197 (2010)

Wright, S.: On the nature of size factors. Genetics 3(4), 367-374 (1918)

Publisher's Note Springer Nature remains neutral with regard to jurisdictional claims in published maps and institutional affiliations.

\section{Authors and Affiliations}

\section{Rosa Fabbricatore ${ }^{1} \cdot$ Maria lannario ${ }^{2}$ (D) $\cdot$ Rosaria Romano ${ }^{3} \cdot$ Domenico Vistocco ${ }^{2}$ (i)}

Rosa Fabbricatore

rosa.fabbricatore@unina.it

Rosaria Romano

rosaroma@unina.it

Domenico Vistocco

domenico.vistocco@unina.it

1 Department of Social Sciences, University of Naples Federico II, Vico Monte della Pietà, 1, Naples 80138, Italy

2 Department of Political Sciences, University of Naples Federico II, Via L. Rodinó, 22, Naples 80138, Italy

3 Department of Economics and Statistics, University of Naples Federico II, Via Cintia, 21, Naples 80126, Italy 